|| ISSN(online): 2589-8698 || ISSN(print): 2589-868X || International Journal of Medical and Biomedical Studies

Available Online at www.ijmbs.info

Volume 3, Issue 2; February: 2019; Page No. 116-119

PubMed (National Library of Medicine ID: 101738825)

Index Copernicus Value 2017: 40.03

\title{
TO FIND RELATIONSHIP BETWEEN COLONIC MUCOSAL CHANGES IN PATIENTS OF LIVER CIRRHOSIS WITH PORTAL HYPERTENSION.
}

\author{
Dr. Prashanth P. N. (Ex-Resident) ${ }^{1}$ \& Ankit Meshram (Ex-Resident) ${ }^{2}$ \\ ${ }^{1 \& 2}$ Dept. of General Medicine, Mahatma Gandhi Memorial Medical College\& Maharaja Yashwantrao \\ Hospital Indore
}

Article Info: Received 30 January 2019; Accepted 21 February. 2019

Cite this article as: N., Dr. P. P., \& Meshram, A. (2019). TO FIND RELATIONSHIP BETWEEN COLONIC MUCOSAL CHANGES IN PATIENTS OF LIVER CIRRHOSIS WITH PORTAL HYPERTENSION. International Journal of Medical and Biomedical Studies, 3(2).

DOI: https://doi.org/10.32553/ijmbs.v3i2.116

Address for Correspondence: Ankit Meshram, Dept. of General Medicine, Mahatma Gandhi Memorial Medical College\& Maharaja Yashwantrao Hospital Indore

Conflict of interest: No conflict of interest.

\section{Abstract}

Background: The aim of the study is to find relationship between Colonic Mucosal changes in patients of Liver Cirrhosis with Portal Hypertension conducted at MGM Medical College \& M. Y. Hospital, Indore for one year.

Result: The commonest symptom in patients was abdominal distension 30 (100\%), next common was jaundice 20 (66.7\%), malena 17 (56.7\%), hemetemesis 10(33.3\%), hematochezia 10(33.3\%), and pruritis $2(6.6 \%)$ was noted.

It is evident from table no .13 that out of 30 patients, serum prothrombin time was prolonged in 30 (100\%) patients, serum albumin was decreased in 20 (66.7\%) patients, platelet count was decreased in $16(53.3 \%)$, serum bilirubin was raised in 14 (46.7\%) patients , SGOT/SGPT was raised in 17 (56.7\%) patients.

Conclusion: Our study states that most of the changes which we found on colonoscopic studies were similar to other studies. The only finding which we got in excess in comparison to other studies was colitis like abnormality which was $73.3 \%$ which may be probably due to chronic intestinal infections which occur in our country.

Keywords: Colonic Mucosal, Liver Cirrhosis, Portal, Hypertension.

\section{Introduction:}

Cirrhosis is a pathologically defined entity that is associated with a spectrum of characteristic clinical manifestations. The cardinal pathological features reflect irreversible chronic injury of the hepatic parenchyma and include extensive fibrosis In association with the formation of regenerative nodules. These features result from hepatocyte necrosis, collapse of the supporting reticulin network with subsequent connective tissue deposition, distortion of the vascular bed, and nodular regeneration of remaining liver parenchyma $^{[1]}$.

Cirrhosis represents the final common histologic pathway for a wide variety of chronic liver diseases. The term cirrhosis was first introduced by Laennec in 1826. It is derived from the Greek term scirrhus and is used to describe the orange or tawny surface of the liver seen at autopsy. 
Chronic liver disease and cirrhosis result in about 35,000 deaths each year in the United States. Cirrhosis is the ninth leading cause of death in the United States and is responsible for $1.2 \%$ of all US deaths. Many patients die from the disease in their fifth or sixth decade of life. Each year, 2000 additional deaths are attributed to fulminant hepatic failure (FHF). FHF may be caused viral hepatitis (e.g., hepatitis A and B), drugs (e.g. acetaminophen), toxins (e.g. Amanita phalloides, the yellow death-cap mushroom), autoimmune hepatitis, Wilson disease, and a variety of less common etiologies. Cryptogenic causes are responsible for one third of fulminant cases. Patients with the syndrome of FHF have a $50-80 \%$ mortality rate unless they are salvaged by liver transplantation. ${ }^{[2]}$

\section{Material \& Method}

The study was carried out on 30 patients of liver cirrhosis with portal hypertension, both from inpatients admitted in medicine wards and outpatients attending medicine OPD and gastroenterology OPD at MGM Medical College \& M. Y. Hospital, Indore (M.P) from One year. The selection of patients was done by Simple Sampling method.

Data collected from each patient including age, gender, location, symptoms at the time colonoscopy, alcohol use, cigarette use, aspirin use, NSAID use, aetiology of Cirrhosis, Child Pugh class, history of upper $\mathrm{G}$ I bleeding, previous treatment of oesophageal varices, upper $\mathrm{G}$ I tract abnormalities in those who underwent upper $G$ I endoscopy.
A detailed clinical assessment was done in all cases including both general physical and systemic examination.

Patients will be further evaluated with various investigations including CBC, RBS, RFT's, LFT's, PT with INR, Urine R/M, USG abdomen, Chest $X$ ray, Serum electrolytes, HBsAg test, liver biopsy and UGI endoscopy before undergoing colonoscopy .

Cirrhosis was confirmed by histology or by compatible physical findings, laboratory tests, and radiographic features. Portal hypertension was documented by endoscopic or radiographic evidence of oesophageal, gastric, or intraabdominal Varices. The severity of cirrhosis was graded using the child Pugh classification.

\section{INCLUSION CRITERIA}

1. Patient of liver cirrhosis with portal hypertension

2. Age group $10-60 \mathrm{yrs}$

3. No history of any antecedent long standing illness in the form of tuberculosis, IHD etc.,

\section{EXCLUSION CRITERIA}

1. Presence of any infection at the time of study

2. Co-morbid conditions

3. Liver malignancy

4. Cardiac diseases

5. Massive ascitis

6. Hepatic failure

7. Inadequate bowel preparation

8. Non cirrhotic liver disease

\section{Results}

Table 1: Symptom profile of cases

\begin{tabular}{|l|l|l|}
\hline SYMPTOMS & NO OF CASES (N) & $\%$ \\
\hline JAUNDICE & 20 & $66.7 \%$ \\
\hline ABDOMINAL DISTENSION & 30 & $100 \%$ \\
\hline HEMETEMESIS & 10 & $33.3 \%$ \\
\hline MALENA & 17 & $56.7 \%$ \\
\hline HEMATOCHEZIA & 10 & $33.3 \%$ \\
\hline PRURITIS & 2 & $6.6 \%$ \\
\hline
\end{tabular}


The commonest symptom in patients was abdominal distension $30(100 \%)$, next common was jaundice $20(66.7 \%)$, malena $17(56.7 \%)$, hemetemesis $10(33.3 \%)$, hematochezia $10(33.3 \%)$, and pruritis $2(6.6 \%)$ was noted.

\section{Table 2: Investigation profile of cases}

\begin{tabular}{|l|l|l|l|l|}
\hline \multirow{2}{*}{ INVESTIGATIONS } & \multicolumn{2}{|l|}{ NORMAL } & \multicolumn{2}{l|}{ ABNORMAL } \\
\cline { 2 - 5 } & NO & $\%$ & NO & $\%$ \\
\hline PLATELET COUNT & 14 & $46.7 \%$ & 16 & $53.3 \%$ \\
\hline S. BILIRUBIN & 16 & $53.3 \%$ & 14 & $46.7 \%$ \\
\hline SGOT/SGPT & 13 & $43.3 \%$ & 17 & $56.7 \%$ \\
\hline ALK PHOSPHATASE & 3 & $10 \%$ & 27 & $90 \%$ \\
\hline S. ALBUMIN & 10 & $33.3 \%$ & 20 & $66.7 \%$ \\
\hline PROTHROMBIN TIME & 0 & $0 \%$ & 30 & $100 \%$ \\
\hline
\end{tabular}

It is evident from table no .13 that out of 30 patients, serum prothrombin time was prolonged in $30(100 \%)$ patients, serum albumin was decreased in $20(66.7 \%)$ patients, platelet count was decreased in $16(53.3 \%)$, serum bilirubin was raised in $14(46.7 \%)$ patients , SGOT/SGPT was raised in 17 (56.7\%) patients.

\section{Discussion}

Several studies have described the colonic findings associated with cirrhosis and portal hypertension $^{[3,4]}$. The features of portal hypertensive colopathy are not well defined but have included vascular lesions, colitis like abnormalities, rectal varices and haemorrhoids or a combination of these findings ${ }^{[5]}$.

There is confusion regarding the diagnostic criteria and clinical significance of this condition. This might be attributable to imprecise terminology, lack of uniform endoscopic descriptions, interobserver variability, and the absence of distinctive histopathologic features.

Various vascular abnormalities have been observed in the mucosa of upper gastrointestinal tract of cirrhotic patients, including gastro esophageal varices and gastric antral vascular ectasia ${ }^{[6]}$.These vascular lesions account for most of the upper gastrointestinal bleeding in cirrhotic patients. Similarly, vascular ectasias and varices may occur in the colonic mucosa of cirrhotic patients, and bleeding from these vascular lesions was reported ${ }^{[7]}$.

\section{Conclusion}

Our study states that most of the changes which we found on colonoscopic studies were similar to other studies. The only finding which we got in excess in comparison to other studies was colitis like abnormality which was $73.3 \%$ which may be probably due to chronic intestinal infections which occur in our country.

\section{References}

1. Bruce R. Bacon. Cirrhosis and its complications. Harrison's Principles of Internal Medicine, $17^{\text {th }}$ edition, Volume 2, Page 1971-80.

2. Rabinovitz $M$, Schade RR, Dindzans VJ, Belle $\mathrm{SH}$, Van Thiel DH, Gavaler JS. Colonic disease in cirrhosis: an endoscopic evaluation in 412 patients Gastroenterology 1990; 99: 195199.

3. Kozarek RA, Botoman VA, Bredfelt JE, Roach JM, Patterson DJ, Ball TJ, Portal Colopathy: Prospective study of colonoscopy in patients with portal hypertension. Gastroenterology 1991; 101: 1192-1197.

4. Siddharth Ganguly, Shiv k.Sarin, Vivek Bhatia and Deepak Lahoti. The prevalence and spectrum of colonic lesions in patients with cirrhotic and noncirrhotic portal hypertension. Hepatology Volume 21,Issue 5,May1995,Pages1226-1231. 
Dr. Prashanth P. N. et al, International Journal of Medical and Biomedical Studies (IJMBS)

5. Viggiano TR, Gostou CJ. Portal hypertensive intestinal vasculopathy: a review of the clinical, endoscopic, and histopathlogic features. Am J Gastroenterol 1992; 87: 944954.

6. Arendt TM, Barten V, and Lakner V, Arendt R. Diffuse gastric antral vascular ectasia: cause of chronic gastrointestinal blood loss. Endoscopy 1987; 19: 218-220.

7. Naveau S, Bedossa P, Poynard T, Mory B, Chaput JC. Portal hypertensive colopathy: a new entity. Dig Dis Sci 1991; 36: 1774-1781. 